\title{
Comparison of 30-day outcomes of coronary artery bypass grafting surgery verus hybrid coronary revascularization stratified by SYNTAX and euroSCORE
}

\author{
Marzia Leacche, MD, John G. Byrne, MD, Natalia S. Solenkova, MD, PhD, Brendan Reagan, MD, \\ Tahir I. Mohamed, MD, PhD, Joseph L. Fredi, MD, and David X. Zhao, MD
}

\begin{abstract}
Objective: The optimal treatment of multivessel coronary artery disease is not well established. Hybrid coronary revascularization by combining the left internal mammary artery-left anterior descending artery graft and drug-eluting stents in non-left anterior descending artery territories might offer superior results compared with sole coronary artery bypass grafting or sole percutaneous coronary intervention.
\end{abstract}

\begin{abstract}
Methods: We retrospectively analyzed the 30-day outcomes of 381 consecutive patients undergoing coronary artery bypass grafting $(n=301)$ vs hybrid coronary revascularization $(n=80)$. In a $2 \times 2$ matrix, the 2 groups were stratified by the Synergy Between Percutaneous Coronary Intervention With Taxus and Cardiac Surgery (SYNTAX) score ( $\leq 32$ vs $\geq 33$ ) and the European System for Cardiac Operative Risk Evaluation (euroSCORE) $(<5$ vs $\geq 5$ ). The composite endpoint (death from any cause, stroke, myocardial infarction, low cardiac output syndrome) and secondary endpoints (worsening postprocedural renal function and bleeding) were determined.
\end{abstract}

Results: After stratification using the SYNTAX and the euroSCORE, the preoperative characteristics were similar within the 4 groups, except for the $\geq 33$ SYNTAX/ $>5$ euroSCORE. The hybrid coronary revascularization patients were older (77 vs 65 years, $P=.001$ ). The postoperative outcomes using combined SYNTAX and the euroSCORE stratification showed a similar rate of the composite endpoint for all groups except for patients with $\geq 33$ SYNTAX/ $>5$ euroSCORE $(0 \%$ for the coronary artery bypass grafting group vs $33 \%$ for the hybrid coronary revascularization group, $P=.001)$. An analysis of the secondary endpoint showed similar results across all groups, except for in the $\geq 33 \mathrm{SYNTAX} />5$ euroSCORE group, in which bleeding (re-exploration for bleeding and transfusion $>3$ packed red blood cell units per patient) was $44 \%$ in the hybrid coronary revascularization group vs $11 \%$ in the coronary artery bypass grafting group $(P=.05)$.

Conclusions: Hybrid coronary revascularization is a safe alternative to coronary artery bypass grafting in many patients with multivessel coronary artery disease. However, in high-risk patients with complex coronary artery disease ( $\geq 33$ SYNTAX/ $>5$ euroSCORE), coronary artery bypass grafting is superior to hybrid coronary revascularization. (J Thorac Cardiovasc Surg 2013;145:1004-12)

Earn CME credits at

http://cme.ctsnetjournals.org

The optimal revascularization for multivessel coronary artery disease (CAD) remains controversial. Coronary artery bypass grafting $(\mathrm{CABG})$ offers superior outcomes for

\footnotetext{
From the Division of Cardiovascular Medicine, Vanderbilt Heart and Vascular Institute, Nashville, Tenn.

Funding and technical support for this project were provided by the Vanderbilt Heart and Vascular Institute and the Cardiac Surgery Research Fund of Vanderbilt University Medical Center.

Disclosures: Authors have nothing to disclose with regard to commercial support. Received for publication Oct 3, 2011; revisions received March 6, 2012; accepted for publication March 22, 2012; available ahead of print April 27, 2012.

Address for reprints: David X. Zhao, MD, Division of Cardiovascular Medicine, Vanderbilt Heart and Vascular Institute, Nashville, TN 37232-8802 (E-mail: david.zhao@vanderbilt.edu).

0022-5223/\$36.00

Copyright $(2) 2013$ by The American Association for Thoracic Surgery doi: $10.1016 /$ j.jtcvs.2012.03.062
}

patients with diabetes and complex lesions, primarily owing to the left internal mammary artery (LIMA) to the left anterior descending (LAD) artery graft. ${ }^{1,2}$ The excellent long-term patency of the LIMA-LAD graft contrasts with the rate of early saphenous vein graft (SVG) failure $(6.2 \%-30 \%$ at 12 months $),{ }^{2-4}$ which might account for the durable clinical benefit of CABG. In non-LAD coronary arteries, the 12-month rate of drug-eluting stent (DES) restenosis and thrombosis after percutaneous coronary intervention (PCI) is lower than the rate of SVG failure. ${ }^{5}$ Therefore, PCI with DES might be a reasonable alternative to SVG for revascularization of non-LAD coronary arteries.

Thus, hybrid coronary revascularization (HCR), combining the LIMA-LAD graft and DES to non-LAD vessels, might become a superior revascularization alternative in multivessel CAD. Several observational studies, including Vanderbilt's experience, ${ }^{6}$ have demonstrated that a hybrid strategy is safe, with short-term outcomes similar to those of standard CABG. However, the indication for, and safety of, HCR compared with standard CABG are not well 

Abbreviations and Acronyms
BMS = bare metal stent
$\mathrm{CABG}=$ coronary artery bypass grafting
$\mathrm{CAD}=$ coronary artery disease
DES = drug-eluting stent
HCR = hybrid coronary revascularization
LAD = left anterior descending (artery)
LIMA $=$ left internal mammary artery
MACCE $=$ major adverse cardiovascular and
PCI = percutaneous coronary artery intervention
STS $=$ Society of Thoracic Surgeons
SVG $=$ saphenous vein graft

Patients who received stents to the graft conduits (SVG or LIMA, $\mathrm{n}=27$ ) or native LAD (because of a failed LIMA-LAD graft, $n=2$ ) were excluded from the present analysis. Patients who received stents to non-LAD native vessel because of failed SVG grafts $(n=4)$ were included in the analysis. All hybrid patients received clopidogrel $75 \mathrm{mg}$ /day for at least 12 months. Unfractionated heparin was used for both PCI and CABG. Heparin was reversed by protamine at the end of $\mathrm{CABG}$ in all patients. A sheath had been placed in the left or right femoral artery using the modified Seldinger technique before anticoagulation with heparin. At the end of surgery, the sheath was removed after the heparin was reversed with protamine, and a Syvek Patch (Marine Polymer Technologies, Danvers, Mass) was applied with 12 minutes of manual compression of the groin.

\section{Statistical Analysis}

The data are expressed as the mean \pm standard deviation or percentages. For continuous variables, a Mann-Whitney $U$ test was used, and the data are expressed as the median. The 2-tailed Fischer exact test was used for categorical variables. Data analysis and statistical analysis were performed using STATA, version 9.0 for Windows (StataCorp, College Station, Tex).

established. In the present study, we compared the 30-day outcomes of HCR and standard CABG in patients stratified by the complexity of CAD (Synergy Between Percutaneous Coronary Intervention With Taxus and Cardiac Surgery [SYNTAX] score) ${ }^{2,7}$ and surgical risk profile (European System for Cardiac Operative Risk Evaluation [euroSCORE]). ${ }^{8}$

\section{METHODS}

After obtaining institutional review board approval, we retrospectively collected data for 500 consecutive patients who had undergone CABG with or without concomitant PCI from April 2005 to March 2009. Patients with multivessel CAD involving the LAD artery and at least 1 other major epicardial artery or left main disease were included in the present study. Patients with concomitant valvular surgical procedures $(n=31)$, singlevessel CAD $(n=33)$, previous CABG with patent grafts $(n=9)$, PCI without stenting as a "bridge" to CABG $(n=2)$, or post-CABG PCI $(n=27)$ were excluded. Preprocedural coronary angiographic data were not available for review in 8 patients. Thus, $301 \mathrm{CABG}$ and $80 \mathrm{HCR}$ patients from our group practice were analyzed in the present study. The SYNTAX score for each patient was calculated by 2 cardiologists using the SYNTAX score algorithm, as previously described. ${ }^{7}$ The euroSCORE for each patient was also calculated. ${ }^{8}$ Patients were stratified into 4 groups according to the SYNTAX score ( $\leq 32$ vs $\geq 33$ ) and euroSCORE ( $\leq 5$ vs $>5$ ).

A comparison between CABG and HCR within these 4 risk-stratified groups was performed. The primary clinical endpoint was a composite major adverse cardiovascular and cerebral events (MACCE) endpoint, including death from any cause, stroke, myocardial infarction, and low cardiac output syndrome during the 30 days after the procedure. The secondary clinical endpoints were worsening postprocedural renal function and bleeding complication during the 30 days after procedure.

All patients enrolled in the study were referred for coronary artery bypass surgery according to the clinical indications. For HCR, the cardiac surgeon and interventional cardiologist both reviewed the coronary angiographic data in advance. The hybrid approach was presented as an alternative approach to CABG to the patient, and separate consent was obtained. Patients who underwent a planned hybrid procedure received 300 $\mathrm{mg}$ of clopidogrel immediately before induction. A total of 20 patients $(25 \%)$ underwent an "unplanned" hybrid procedure that was performed because of intraoperative findings such as graft defects on completion angiography, poor conduits, or a poor target vessel. The unplanned hybrid patients received $300 \mathrm{mg}$ clopidogrel by way of a nasogastric tube at PCI.

\section{RESULTS}

\section{Stratification by SYNTAX Score Only}

Patients with SYNTAX score of 32 or less. A total of 293 patients (226 CABG, $67 \mathrm{HCR}$ ) had a SYNTAX score of 32 or less (mean, $21 \pm 8$ ). The HCR group had more 3-vessel CAD ( $82 \%$ vs $66 \%, P=.015)$, and the CABG group had more 2-vessel CAD (30\% vs $15 \%, P=.018)$. Compared with the CABG group, the HCR group had shorter aortic crossclamp ischemic times but a longer total operative time. Other preoperative, intraoperative, and postoperative data were similar among the groups (Table 1). In the HCR group, of 67 patients, $62(93 \%)$ received a DES and 7 $(7 \%)$ of 69 patients received a bare metal stent (BMS). Each patient received a mean of $2 \pm 1.3$ stents. The median number of bypass grafts per patient was 2 in each group (HCR and CABG patients).

Patients with SYNTAX score of 33 or greater. A total of 88 patients (75 CABG, $13 \mathrm{HCR}$ ) had a SYNTAX score of 33 or greater (mean, $37 \pm 4$ ). Compared with patients undergoing $\mathrm{CABG}$, the patients undergoing $\mathrm{HCR}$ were older (median age, 74 vs 62 years; $P=.015$ ) and had a greater euroSCORE (median, 6 vs $4 ; P=.045$ ). The cardiopulmonary bypass time and ischemic times were shorter in the HCR group than in the CABG group. The composite MACCE was greater in the HCR group than in the CABG group, primarily owing to increased mortality in the HCR group (HCR, 3/13 [23\%] vs CABG, $0 / 75[0 \%] ; P=.003$; Table 2 ). The mean number of stents per patient in the HCR group was $2.3 \pm 0.8$, with $77 \%$ (10/13) receiving DES and 23\% (3/13) receiving BMS. The median number of grafts per patient in the CABG group was 2 (range, 1-5) and 1 (range, 1-2) in the HCR group $(P=.001$; Table 2$)$.

\section{Stratification by euroSCORE Only}

Patients with euroSCORE of 5 or less. A total of 239 patients (193 CABG and $46 \mathrm{HCR}$ ) had a euroSCORE of 5 or 
TABLE 1. Preoperative, intraoperative, and postoperative data for SYNTAX $\leq 32(\mathbf{n}=\mathbf{2 9 3})$

\begin{tabular}{|c|c|c|c|}
\hline Variable & $\begin{array}{c}\text { CABG } \\
(\mathbf{n}=226)\end{array}$ & $\begin{array}{c}\text { HCR } \\
(n=67) \\
\end{array}$ & $\begin{array}{c}P \\
\text { value }\end{array}$ \\
\hline \multicolumn{4}{|l|}{ Preoperative data } \\
\hline Age (y) & $63(32-89)$ & $62(39-85)$ & .707 \\
\hline Men & $169(75)$ & $53(79)$ & .519 \\
\hline Diabetes & $86(38)$ & $28(42)$ & .669 \\
\hline Hypertension & $186(82)$ & $59(88)$ & .348 \\
\hline Dyslipidemia & $170(75)$ & $49(73)$ & .750 \\
\hline Cardiogenic shock & $3(1)$ & $1(1)$ & 1.000 \\
\hline CHF & $25(11)$ & $5(7)$ & .495 \\
\hline COPD & $48(21)$ & $17(26)$ & .502 \\
\hline History of stroke & $18(8)$ & $3(4)$ & .427 \\
\hline PVD & $38(17)$ & $15(22)$ & .366 \\
\hline Carotid artery stenosis & $34(15)$ & $11(16)$ & .847 \\
\hline Inotropic support & $3(1)$ & $1(1)$ & 1.000 \\
\hline Preoperative IABP & $8(4)$ & $2(3)$ & 1.000 \\
\hline Valve disease & $34(15)$ & $7(10)$ & .425 \\
\hline Previous cardiac surgery & $0(0)$ & $1(1)$ & .229 \\
\hline Acute MI & $34(15)$ & $11(16)$ & .847 \\
\hline UA & $126(56)$ & $35(52)$ & .675 \\
\hline 2-Vessel disease & $67(30)$ & $10(15)$ & .018 \\
\hline$\geq 3$-Vessel disease & $149(66)$ & $55(82)$ & .015 \\
\hline Left main disease & $60(27)$ & $11(16)$ & .105 \\
\hline Proximal LAD & $87(39)$ & $23(34)$ & .568 \\
\hline LVEF & $55(10-80)$ & $50(20-70)$ & .590 \\
\hline Emergent/urgent status & $140(62)$ & $41(61)$ & 1.000 \\
\hline NYHA class & $2(1-4)$ & $1(1-4)$ & .154 \\
\hline $\begin{array}{l}\text { Baseline creatinine } \\
\geq 1.5 \mathrm{mg} / \mathrm{dL}\end{array}$ & $14(6)$ & $7(10)$ & .272 \\
\hline euroSCORE & $4(0-14)$ & $4(0-12)$ & .948 \\
\hline \multicolumn{4}{|l|}{ Intraoperative data } \\
\hline Planned & & $49 / 67(73)$ & \\
\hline Off pump & $35(15)$ & $15(22)$ & .198 \\
\hline Grafts (n) & $2(1-5)$ & $2(1-5)$ & .001 \\
\hline OR time (min) & $374(138-664)$ & $411(230-744)$ & .001 \\
\hline CPB time $(\min )$ & $92(28-284)$ & $76(33-175)$ & .001 \\
\hline Aortic crossclamp time (min) & $64(12-152)$ & $51(18-111)$ & .001 \\
\hline \multicolumn{4}{|l|}{ Perioperative outcomes } \\
\hline Operative mortality & $5(2)$ & $1(1)$ & 1.000 \\
\hline Length of stay (d) & $6(1-32)$ & $5(3-97)$ & .766 \\
\hline \multicolumn{4}{|l|}{ Postoperative complications } \\
\hline PCVA & $3(1)$ & $1(1)$ & 1.000 \\
\hline ARF/RFHD & $8(4)$ & $2(3)$ & 1.000 \\
\hline Bleeding/PRBC $\geq 3$ & $38(17)$ & $12(18)$ & .854 \\
\hline Reoperation for bleeding & $7(3)$ & $3(4)$ & .701 \\
\hline Tracheostomy & $2(1)$ & $2(3)$ & .225 \\
\hline New atrial fibrillation & $49(22)$ & $11(16)$ & .393 \\
\hline PLCOS & $10(4)$ & $0(0)$ & .124 \\
\hline Composite outcome* & $16(7)$ & $3(4)$ & .579 \\
\hline
\end{tabular}

Data are presented as the median (range) or number (percentage). SYNTAX, Synergy Between Percutaneous Coronary Intervention With Taxus and Cardiac Surgery; $C A B G$, coronary artery bypass grafting; $H C R$, hybrid coronary revascularization; $C H F$, congestive heart failure; $C O P D$, chronic obstructive pulmonary disease; $P V D$, peripheral vascular disease; $I A B P$, intra-aortic balloon pump; $L A D$, left anterior descending (artery); $M I$, myocardial infarction; $U A$, unstable angina; $L V E F$, left ventricular ejection fraction; NYHA, New York Heart Association (functional classification); euroSCORE, European System for Cardiac Operative Risk Evaluation; $O R$, operating room; $C P B$, cardiopulmonary bypass; $P C V A$, postoperative cerebrovascular accident; $A R F / R F H D$, acute renal failure/renal failure requiring hemodialysis; PLCOS, postoperative low cardiac output syndrome. *Composite cardiac and cerebrovascular outcome: operative mortality, MI, PCVA, PLCOS.
TABLE 2. Preoperative, intraoperative, and postoperative data for SYNTAX $\geq 33(n=88)$

\begin{tabular}{|c|c|c|c|}
\hline Variable & $\begin{array}{c}\text { CABG } \\
(\mathbf{n}=75)\end{array}$ & $\begin{array}{c}\text { HCR } \\
(n=13) \\
\end{array}$ & $\begin{array}{c}P \\
\text { value } \\
\end{array}$ \\
\hline \multicolumn{4}{|l|}{ Preoperative data } \\
\hline Age (y) & $62(36-83)$ & $74(53-84)$ & .015 \\
\hline Men & $62(83)$ & $8(62)$ & .129 \\
\hline Diabetes & $24(32)$ & $4(31)$ & 1.000 \\
\hline Hypertension & $65(87)$ & $10(77)$ & .399 \\
\hline Dyslipidemia & $59(79)$ & $9(69)$ & .481 \\
\hline Cardiogenic shock & $1(1)$ & $0(0)$ & 1.000 \\
\hline $\mathrm{CHF}$ & $11(15)$ & $1(5)$ & .450 \\
\hline COPD & $23(31)$ & $2(16)$ & .334 \\
\hline History of stroke & $11(15)$ & $2(10)$ & .729 \\
\hline PVD & $11(15)$ & $4(31)$ & .224 \\
\hline Carotid artery stenosis & $10(13)$ & $2(15)$ & 1.000 \\
\hline Inotropic support & $2(3)$ & $0(0)$ & 1.000 \\
\hline Preoperative IABP & $2(3)$ & $1(5)$ & .512 \\
\hline Valve disease & $7(9)$ & $2(16)$ & .616 \\
\hline Previous cardiac surgery & $3(4)$ & $0(0)$ & 1.000 \\
\hline Acute MI & $9(12)$ & $2(15)$ & .663 \\
\hline UA & $34(45)$ & $6(46)$ & 1.000 \\
\hline 2-Vessel disease & $14(19)$ & $3(23)$ & .710 \\
\hline$\geq 3$-Vessel disease & $55(73)$ & $10(77)$ & 1.000 \\
\hline Left main disease & $30(40)$ & $3(23)$ & .355 \\
\hline Proximal LAD & $26(35)$ & $4(31)$ & 1.000 \\
\hline $\mathrm{EF}$ & $50(10-70)$ & $50(20-65)$ & .415 \\
\hline Emergent/urgent status & $38(51)$ & $7(54)$ & 1.000 \\
\hline NYHA class & $2(1-4)$ & $2(1-3)$ & .849 \\
\hline Baseline creatinine $\geq 1.5 \mathrm{mg} / \mathrm{dL}$ & $12(16)$ & $0(0)$ & .200 \\
\hline euroSCORE & $4(0-15)$ & $6(1-14)$ & .045 \\
\hline \multicolumn{4}{|l|}{ Intraoperative data } \\
\hline Planned & & $11 / 13(85)$ & \\
\hline Off pump & $12(16)$ & $4(31)$ & .243 \\
\hline Grafts (n) & $2(1-5)$ & $1(1-2)$ & .001 \\
\hline OR time (min) & $378(250-667)$ & $405(294-549)$ & .404 \\
\hline CPB time (min) & $91(32-153)$ & $64(50-159)$ & .090 \\
\hline Aortic crossclamp time (min) & $61(21-108)$ & $38(23-75)$ & .041 \\
\hline \multicolumn{4}{|l|}{ Perioperative data } \\
\hline Operative mortality & $0(0)$ & $3(23) *$ & .003 \\
\hline Length of stay (d) & $6(3-63)$ & $6(1-32)$ & .364 \\
\hline \multicolumn{4}{|l|}{ Postoperative complications } \\
\hline PCVA & $1(1)$ & $1(8)$ & .275 \\
\hline ARF/RFHD & $4(5)$ & $0(0)$ & 1.000 \\
\hline Bleeding/PRBC $\geq 3 \mathrm{U}$ & $10(13)$ & $4(31)$ & .210 \\
\hline Reoperation for bleeding & $0(0)$ & $0(0)$ & \\
\hline Tracheostomy & $1(1)$ & $2(15)$ & .056 \\
\hline New atrial fibrillation & $17(23)$ & $4(31)$ & .501 \\
\hline PLCOS & $3(4)$ & $2(15)$ & .156 \\
\hline Composite outcome $\dagger$ & $4(5)$ & $4(30)$ & .015 \\
\hline
\end{tabular}

Data are presented as the median (range) or number (percentage). SYNTAX, Synergy Between Percutaneous Coronary Intervention With Taxus and Cardiac Surgery; $C A B G$, coronary artery bypass grafting; $H C R$, hybrid coronary revascularization; $C H F$, congestive heart failure; $C O P D$, chronic obstructive pulmonary disease; $M I$, myocardial infarction; $U A$, unstable angina; $P V D$, peripheral vascular disease; $I A B P$, intra-aortic balloon pump; $L A D$, left anterior descending (artery); $E F$, ejection fraction; NYHA, New York Heart Association (functional classification); euroSCORE, European System for Cardiac Operative Risk Evaluation; $O R$, operating room; $C P B$, cardiopulmonary bypass; $P C V A$, postoperative cerebrovascular accident; $A R F / R F H D$, acute renal failure/renal failure requiring hemodialysis; $P L C O S$, postoperative low cardiac output syndrome. *HCR group, 2 planned and 1 unplanned. †Composite cardiac and cerebrovascular outcome: operative mortality, MI, PCVA, PLCOS. 
TABLE 3. Preoperative, intraoperative, and postoperative data for euroSCORE $\leq \mathbf{5}(\mathbf{n}=\mathbf{2 3 9})$

\begin{tabular}{|c|c|c|c|}
\hline Variable & $\begin{array}{c}\text { CABG } \\
(\mathbf{n}=\mathbf{1 9 3})\end{array}$ & $\begin{array}{c}\text { HCR } \\
(n=46)\end{array}$ & $\begin{array}{c}P \\
\text { value }\end{array}$ \\
\hline \multicolumn{4}{|l|}{ Preoperative data } \\
\hline Age (y) & $59(32-80)$ & $58(39-75)$ & .310 \\
\hline Men & $157(81)$ & $38(83)$ & 1.000 \\
\hline Diabetes & $65(34)$ & $21(46)$ & .171 \\
\hline Hypertension & $152(79)$ & $39(85)$ & .419 \\
\hline Dyslipidemia & $155(80)$ & $37(80)$ & 1.000 \\
\hline Cardiogenic shock & $1(1)$ & $1(2)$ & 349 \\
\hline $\mathrm{CHF}$ & $13(7)$ & $2(4)$ & .742 \\
\hline COPD & $36(19)$ & $7(16)$ & .830 \\
\hline History of stroke & $11(6)$ & $0(0)$ & .130 \\
\hline PVD & $17(9)$ & $8(17)$ & 107 \\
\hline Carotid artery stenosis & $13(7)$ & $5(11)$ & .357 \\
\hline Inotropic support & $2(1)$ & $1(2)$ & .475 \\
\hline Preoperative IABP & $2(1)$ & $1(2)$ & .475 \\
\hline Valve disease & $14(7)$ & $2(4)$ & .744 \\
\hline Previous cardiac surgery & $0(0)$ & $0(0)$ & \\
\hline Acute MI & $17(9)$ & $4(9)$ & 1.000 \\
\hline UA & $97(51)$ & $21(46)$ & .623 \\
\hline 2-Vessel disease & $52(27)$ & $7(15)$ & .127 \\
\hline$\geq 3$-Vessel disease & $1426(65)$ & $38(83)$ & .022 \\
\hline Left main disease & $55(29)$ & $8(17)$ & 140 \\
\hline Proximal LAD & $67(35)$ & $15(33)$ & .864 \\
\hline $\mathrm{EF}$ & $55(15-80)$ & $55(30-70)$ & .942 \\
\hline Emergent/urgent status & $112(58)$ & $24(52)$ & .510 \\
\hline NYHA class & $2(1-4)$ & $1(1-3)$ & .600 \\
\hline $\begin{array}{l}\text { Baseline creatinine } \\
\geq 1.5 \mathrm{mg} / \mathrm{dL}\end{array}$ & $11(6)$ & $3(7)$ & .736 \\
\hline SYNTAX score & $24.5(7-46.5)$ & $22.5(12-41)$ & .188 \\
\hline SYNTAX low score & $80(41)$ & $22(48)$ & .044 \\
\hline SYNTAX medium score & $65(34)$ & $20(43)$ & .044 \\
\hline SYNTAX high score & $48(25)$ & $4(9)$ & .044 \\
\hline euroSCORE & $3(0-5)$ & $2.5(0-5)$ & .606 \\
\hline \multicolumn{4}{|l|}{ Intraoperative data } \\
\hline Planned HCR & & $34 / 46(74)$ & \\
\hline Off pump & $27(14)$ & $7(15)$ & .816 \\
\hline Grafts (n) & $2(1-5)$ & $2(1-4)$ & .001 \\
\hline OR time (min) & 375 (138-667) & $403(230-744)$ & .005 \\
\hline CPB time (min) & $91(28-178)$ & $72(33-143)$ & .001 \\
\hline $\begin{array}{l}\text { Aortic crossclamp } \\
\text { time (min) }\end{array}$ & $64.5(20-147)$ & $50(18-111)$ & .001 \\
\hline \multicolumn{4}{|l|}{ Perioperative outcomes } \\
\hline Operative mortality & $1(1)$ & $2(4)$ & .096 \\
\hline Length of stay (d) & $5(3-33)$ & $5(3-97)$ & .694 \\
\hline
\end{tabular}

less (mean, $2.67 \pm 1.58$ ). The preoperative and postoperative data were similar between the 2 groups. The cardiopulmonary bypass time and ischemic time were shorter in HCR group than in the CABG group (Table 3). In the HCR group, the mean number of stents placed per patient was $2.0 \pm 1.4$, and most patients $(91 \%)$ received a DES. The median number of grafts per patient in the CABG and HCR group was 2 (range, $1-5)$ and 2 (range, $1-4)$, respectively $(P=.001)$.
TABLE 3. Continued

\begin{tabular}{lclr}
\hline \multicolumn{1}{c}{ Variable } & $\begin{array}{c}\text { CABG } \\
(\mathbf{n}=\mathbf{1 9 3})\end{array}$ & $\begin{array}{c}\text { HCR } \\
(\mathbf{n}=\mathbf{4 6})\end{array}$ & $\begin{array}{c}\boldsymbol{P} \\
\text { value }\end{array}$ \\
\hline Postoperative complications & & & \\
PCVA & $1(1)$ & $0(0)$ & 1.000 \\
ARF/RFHD & $6(3)$ & $1(2)$ & 1.000 \\
Bleeding/PRBC $\geq 3 \mathrm{U}$ & $24(12)$ & $8(17)$ & .347 \\
Reoperation for bleeding & $4(2)$ & $3(7)$ & .132 \\
Tracheostomy & $2(1)$ & $2(4)$ & .168 \\
New atrial fibrillation & $37(19)$ & $5(11)$ & .280 \\
PLCOS & $8(4)$ & $0(0)$ & .359 \\
Composite outcome* & $10(5)$ & $3(7)$ & .719 \\
\hline
\end{tabular}

Data are presented as the median (range) or number (percentage). euroSCORE, European System for Cardiac Operative Risk Evaluation; $C A B G$, coronary artery bypass grafting; $H C R$, hybrid coronary revascularization; $C H F$, congestive heart failure; $C O P D$, chronic obstructive pulmonary disease; $P V D$, peripheral vascular disease; $I A B P$, intra-aortic balloon pump; $M I$, myocardial infarction; $U A$, unstable angina; $L A D$, left anterior descending (artery); $E F$, ejection fraction; SYNTAX, Synergy Between Percutaneous Coronary Intervention With Taxus and Cardiac Surgery; $N Y H A$, New York Heart Association (functional classification); $O R$, operating room; $C P B$, cardiopulmonary bypass; $P C V A$, postoperative cerebrovascular accident; $A R F / R F H D$, acute renal failure/renal failure requiring hemodialysis; $P L C O S$, postoperative low cardiac output syndrome. *Composite cardiac and cerebrovascular outcome: operative mortality, MI, PCVA, PLCOS.

Patients with euroSCORE greater than 5. A total of 142 patients (108 CABG and $34 \mathrm{HCR}$ ) had a euroSCORE greater than 5 (mean, $8 \pm 2$ ). The preoperative and postoperative data were similar between the 2 groups. The total operating room time was longer in the HCR group than in the CABG group (Table 4). Of these patients, $85 \%$ received a DES and $15 \%$ a BMS, with a mean number of stents per patient of $2.2 \pm 1.1$. The median number of grafts per patient in the CABG and HCR group was 2 (range, 1-5).

\section{Stratification by Both SYNTAX and euroSCORE $(2 \times 2$ Matrix $)$}

The matrix depicted in Figure 1 is divided by the high and low SYNTAX score and low and high euroSCORE. The columns represent division into high and low SYNTAX scores. The rows represent division into the high and low euroSCORE. Each of the 4 components of the matrix represents a different combination of high and low SYNTAX scores and euroSCOREs and their effect on the 30-day composite endpoint for CABG vs HCR.

Patients with SYNTAX of 32 or less and euroSCORE of 5 or Less. A total of 187 patients (145 CABG, 42 HCR) had low coronary complexity and a low-risk profile. The CABG group had a greater percentage of 3-vessel disease and longer ischemic and cardiopulmonary bypass times than the HCR group. The postoperative outcomes were similar (Appendix Table 1). Of the $42 \mathrm{HCR}$ patients, 93\% received a DES and $7 \%$ a BMS. Each patient received a mean of $2.0 \pm 1.4$ stents. The median number of grafts per patient in the CABG and HCR groups was 2 (range, $1-5)$ and 2 (range, $1-4)$, respectively $(P=.001)$. 
TABLE 4. Preoperative, intraoperative, and postoperative data for euroSCORE $>5(n=142)$

\begin{tabular}{|c|c|c|c|}
\hline Variable & $\begin{array}{c}\text { CABG } \\
(n=108)\end{array}$ & $\begin{array}{c}\text { HCR } \\
(n=34) \\
\end{array}$ & $\begin{array}{c}P \\
\text { value }\end{array}$ \\
\hline \multicolumn{4}{|l|}{ Preoperative data } \\
\hline Age (y) & $71(45-89)$ & $73(45-85)$ & .056 \\
\hline Men & $74(69)$ & $23(68)$ & 1.000 \\
\hline Diabetes & $45(42)$ & $11(32)$ & .422 \\
\hline Hypertension & $99(92)$ & $30(88)$ & .511 \\
\hline Dyslipidemia & $74(69)$ & $21(62)$ & .532 \\
\hline Cardiogenic shock & $3(3)$ & $0(0)$ & 1.000 \\
\hline $\mathrm{CHF}$ & $22(20)$ & $4(12)$ & .317 \\
\hline COPD & $35(33)$ & $12(35)$ & .836 \\
\hline History of stroke & $17(16)$ & $5(15)$ & 1.000 \\
\hline PVD & $32(30)$ & $11(32)$ & .831 \\
\hline Carotid artery stenosis & $31(29)$ & $8(24)$ & .662 \\
\hline Inotropic support & $3(3)$ & $0(0)$ & 1.000 \\
\hline Preoperative IABP & $8(7)$ & $1(3)$ & .687 \\
\hline Valve disease & $27(25)$ & $7(21)$ & .653 \\
\hline Previous cardiac surgery & $2(2)$ & $1(3)$ & .563 \\
\hline Acute MI & $26(24)$ & $9(26)$ & .821 \\
\hline UA & $63(58)$ & $20(59)$ & 1.000 \\
\hline 2-Vessel disease & $29(27)$ & $6(18)$ & .363 \\
\hline$\geq 3$-Vessel disease & $78(72)$ & $27(79)$ & .504 \\
\hline Left main disease & $35(32)$ & $6(18)$ & .129 \\
\hline Proximal LAD & $46(43)$ & $12(35)$ & .550 \\
\hline $\mathrm{EF}$ & $50(10-70)$ & $50(20-65)$ & .695 \\
\hline Emergent/urgent status & $66(61)$ & $24(71)$ & .415 \\
\hline NYHA class & $2(1-4)$ & $2(1-4)$ & .056 \\
\hline $\begin{array}{l}\text { Baseline creatinine } \\
\geq 1.5 \mathrm{mg} / \mathrm{dL}\end{array}$ & $15(14)$ & $4(12)$ & 1.000 \\
\hline SYNTAX score & $27(11-56)$ & $26.5(13-44.5)$ & .920 \\
\hline SYNTAX low score & $35(32)$ & $13(38)$ & .725 \\
\hline SYNTAX medium score & $46(43)$ & $12(35)$ & .725 \\
\hline SYNTAX high score & $27(25)$ & $9(27)$ & .725 \\
\hline euroSCORE & $7(6-15)$ & $8(6-14)$ & .472 \\
\hline \multicolumn{4}{|l|}{ Intraoperative data } \\
\hline Planned HCR & & 26/34 (76) & \\
\hline Off pump & $20(19)$ & $12(35)$ & .058 \\
\hline Grafts (n) & $2(1-5)$ & $2(1-5)$ & .001 \\
\hline OR time (min) & $380(234-558)$ & $418(264-593)$ & .030 \\
\hline CPB time (min) & $93(32-284)$ & $75(36-175)$ & .131 \\
\hline $\begin{array}{l}\text { Aortic crossclamp } \\
\text { time (min) }\end{array}$ & $61.5(12-152)$ & $54.5(21-96)$ & .090 \\
\hline \multicolumn{4}{|l|}{ Perioperative outcomes } \\
\hline Operative mortality & $4(4)$ & $2(6)$ & .630 \\
\hline Length of stay (d) & $6(1-63)$ & $6(1-25)$ & .481 \\
\hline
\end{tabular}

Patients with SYNTAX of 32 or less and euroSCORE greater than 5. The group with a SYNTAX score of 32 or less and euroSCORE greater than 5 included $81 \mathrm{CABG}$ patients and 25 HCR patients. The outcomes were similar, except that the HCR group had a longer operating room time (Appendix Table 2). The mean number of stents placed per patient in the HCR was $2.0 \pm 1.2$, with most $(88 \%)$ receiving a DES. The median number of grafts per patient in
TABLE 4. Continued

\begin{tabular}{lccr}
\hline \multicolumn{1}{c}{ Variable } & $\begin{array}{c}\text { CABG } \\
(\mathbf{n}=\mathbf{1 0 8})\end{array}$ & $\begin{array}{c}\text { HCR } \\
(\mathbf{n}=\mathbf{3 4})\end{array}$ & $\begin{array}{c}\boldsymbol{P} \\
\text { value }\end{array}$ \\
\hline Postoperative complications & & & \\
PCVA & $3(3)$ & $2(6)$ & .593 \\
ARF/RFHD & $6(6)$ & $1(3)$ & 1.000 \\
Bleeding/PRBC $\geq 3 \mathrm{U}$ & $24(22)$ & $8(24)$ & 1.000 \\
Reoperation for bleeding & $3(3)$ & $0(0)$ & 1.000 \\
Tracheostomy & $1(1)$ & $2(6)$ & .142 \\
New atrial fibrillation & $29(27)$ & $10(29)$ & .827 \\
PLCOS & $5(5)$ & $2(6)$ & .673 \\
Composite outcome* & $10(9)$ & $4(12)$ & .743 \\
\hline D
\end{tabular}

Data are presented as the median (range) or number (percentage). euroSCORE, European System for Cardiac Operative Risk Evaluation; $C A B G$, coronary artery bypass grafting; $H C R$, hybrid coronary revascularization; $C H F$, congestive heart failure; $C O P D$, chronic obstructive pulmonary disease; $P V D$, peripheral vascular disease; $I A B P$, intra-aortic balloon pump; $L A D$, left anterior descending (artery); $E F$, ejection fraction; $M I$, myocardial infarction; $U A$, unstable angina; SYNTAX, Synergy Between Percutaneous Coronary Intervention With Taxus and Cardiac Surgery; NYHA, New York Heart Association (functional classification); $O R$, operating room; $C P B$, cardiopulmonary bypass; $P C V A$, postoperative cerebrovascular accident; $A R F / R F H D$, acute renal failure/renal failure requiring hemodialysis; $P L C O S$, postoperative low cardiac output syndrome. *Composite cardiac and cerebrovascular outcome: operative mortality, MI, PCVA, PLCOS.

the $\mathrm{CABG}$ and $\mathrm{HCR}$ groups was 2 (range, 1-4) and 2 (range, $1-5)$, respectively $(P=.001)$.

Patients with SYNTAX of 33 or greater and euroSCORE of 5 or less. The patients with a SYNTAX of 33 or more and euroSCORE of 5 or less included 52 patients (48 CABG, $4 \mathrm{HCR}$ ). The preoperative, intraoperative, and postoperative data were similar (Appendix Table 3). Of the 4 HCR patients, $3(75 \%)$ received a DES and 1 $(25 \%)$ a BMS, for a mean of $2.5 \pm 1.0$ stents placed per patient. The median number of grafts in the CABG and HCR groups was 2 (range, 1-4) and 1 (range, $1-2$ ) respectively $(P=.005)$.

Patients with SYNTAX of 33 or greater and euroSCORE greater than 5. In the final group of 36 patients (27 CABG and $9 \mathrm{HCR}$ ), the HCR patients were older (median age, 77 vs 65 years; $P=.001$ ). The composite MACCE was $33 \%$ in the HCR group and $0 \%$ in the CABG group $(P=.012)$. Bleeding complications and postoperative low cardiac output syndrome were also more frequent in the HCR group (Appendix Table 4). The mean number of stents per patient was $2.4 \pm 0.9$, with most patients receiving DES $(78 \%)$ and fewer $(22 \%)$ BMS. The median number of grafts per patient in the CABG and HCR groups was 2 (range, $1-5)$ and 1 (range, $1-2)$, respectively $(P=.027)$.

\section{DISCUSSION}

The principal finding of our study was that HCR is safe and feasible for many patients with multivessel CAD. However, patients with SYNTAX of 33 or greater and euroSCORE greater than 5 experienced better outcomes with standard CABG than with HCR. The present study focused on the safety of HCR compared with standard CABG. We 


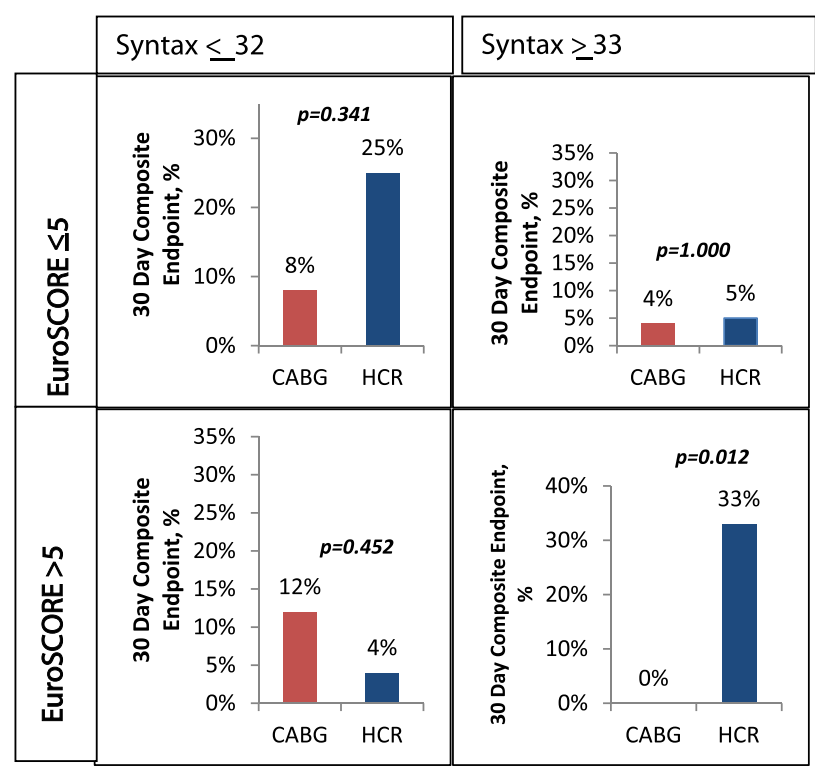

FIGURE 1. The 30-day composite cardiac and cerebrovascular outcomes in the coronary artery bypass grafting $(C A B G)$ group and hybrid coronary revascularization (HCR) stratified by Synergy Between Percutaneous Coronary Intervention With Taxus and Cardiac Surgery (SYNTAX) and European System for Cardiac Operative Risk Evaluation (euroSCORE).

sought to explore the utility of the SYNTAX and euroSCORE to identify patients suitable for HCR. The 30-day rate of MACCE for HCR vs CABG was similar in patients with a low to intermediate SYNTAX score $(\leq 32)$. Among patients in the HCR group with a high SYNTAX score, the rate of MACCE significantly increased, but the outcomes in the CABG group were not influenced by the SYNTAX score. Although the euroSCORE alone did not discern MACCE, the HCR group had significantly greater MACCE compared with the CABG group in patients with a combination of a SYNTAX score of 33 or greater and euroSCORE greater than 5. Similar results were reported after the stratification of patients with 3-vessel disease in the original SYNTAX trial ${ }^{1}$ and Arterial Revascularization Therapies Study Part registry. ${ }^{9}$ These results reflect the fact that the complexity of the coronary lesion directly affects the outcomes of PCI, and the success of CABG is primarily related to the quality of the distal targets and patients' overall health, and not to the coronary lesions themselves. Our findings suggest that HCR should be carefully scrutinized in patients with high $(\geq 33)$ SYNTAX scores, in particular in those with a concomitant high $(>5)$ euroSCORE.

Few series have compared the results of HCR vs CABG. ${ }^{6,10}$ In our previous report of HCR, we did not find significant differences in the 30-day outcomes. ${ }^{6}$ Similarly, in a series of $104 \mathrm{HCR}$ patients with multivessel disease who were propensity matched to 104 off-pump CABG patients, the 30-day outcomes were similar and the MACCE at 18 months of follow-up was better in the HCR than in the off-pump CABG group because of the high rate of readmission to the hospital and neurologic events in the CABG group. ${ }^{10}$ This is in concordance with the observation from the SYNTAX trial, ${ }^{1}$ underscoring the lower invasiveness of PCI and lower stroke rate compared with standard CABG.

The euroSCORE was developed from a multinational European adult cardiac surgery database to provide a simple additive risk model for the European cardiac surgery patients. In North America, the Society of Thoracic Surgeons (STS) established a national adult cardiac surgery database in 1989. The STS has developed an algorithm for the preoperative calculation of risk for CABG surgery using data collected in the STS National Adult Cardiac Surgery Database. Despite substantial demographic differences between the North American patients and European patients, the euroSCORE, when tested using the STS national adult cardiac surgery database, performs well and can be used as a risk stratification tool. ${ }^{11}$ We chose to use the euroSCORE to discern the clinical risk profile of patients instead of the STS risk algorithm because the euroSCORE has been shown to have better discriminative power to predict 30-day mortality compared with the STS clinical algorithm used in coronary artery bypass operations only. ${ }^{12}$ The better discrimination power is related to the significant differences between scores with regard to the initial patient population on which each score design was based.

The SYNTAX score, calculated using lesion assessment based on coronary angiography, provides a useful tool to objectively decide which patient is suitable for PCI vs CABG. The SYNTAX score has not yet been validated for patients with previous intervention (PCI or $\mathrm{CABG}$ ) or in the setting of acute myocardial infarction. In a post hoc analysis of 1397 patients enrolled in the Limus Eluted from A Durable vs ERodable Stent coating (LEADERS) trial, the SYNTAX score was applied to an all-comers population including patients with acute coronary syndromes and with previous PCI and had showed predictive discriminatory power for risk assessment. ${ }^{13}$ In our study, the SYNTAX score provided a useful tool for clinical decision making related to appropriateness of hybrid revascularization vs standard CABG.

\section{Study Limitations}

The present study was an uncontrolled retrospective series, and patient treatment was decided by surgeon and cardiologist preference. The number of HCR patients in the combined SYNTAX and euroSCORE group was small, and this could affect the incidence of events noted in this group. A larger study is needed to better define the clinical outcomes using the SYNTAX and euroSCORE between CABG and HCR. We included patients with acute myocardial infarction and previous PCI, which might have affected the SYNTAX score. Similarly, the euroSCORE has been shown to have lower predictive performance 
for higher scores compared with low-risk scores. Therefore, in the high SYNTAX and high euroSCORE group, the predictive value of the euroSCORE could be affected negatively.

The present study tested the 30-day mortality and other MACCE. We are currently in the process of studying the 1- and 3-year MACCE in both groups.

\section{CONCLUSIONS}

The present study is the first to apply SYNTAX score and euroSCORE to compare the safety outcomes in patients who underwent HCR vs CABG. Both procedures offer equal safety outcomes for most patients. However, in patients with complex coronary disease (as assessed by the SYNTAX score) and a high clinical risk profile (as assessed by the euroSCORE), CABG might offer superior 30-day outcomes. A larger and prospective study with long-term follow-up is necessary to validate these initial findings.

\section{References}

1. Serruys PW, Morice MC, Kappetein AP, et al. Percutaneous coronary intervention versus coronary-artery bypass grafting for severe coronary artery disease. N Engl J Med. 2009;360:961-72.

2. Alexander JH, Hafley G, Harrington RA, et al. Efficacy and safety of edifoligide, an E2F transcription factor decoy, for prevention of vein graft failure following coronary artery bypass graft surgery: PREVENT IV: a randomized controlled trial. JAMA. 2005;294:2446-54

3. Puskas JD, Williams WH, Mahoney EM, et al. Off-pump vs conventional coronary artery bypass grafting: early and 1-year graft patency, cost, and quality-oflife outcomes: a randomized trial. JAMA. 2004;291:1841-9.

4. Balacumaraswami LM, Taggart DP. Intraoperative imaging techniques to assess coronary artery bypass graft patency. Ann Thorac Surg. 2007;83:2251-7.

5. Mauri L, Orav EJ, Kuntz RE. Late loss in lumen diameter and binary restenosis for drug-eluting stent comparison. Circulation. 2005;111:3435-42.

6. Zhao DX, Leacche M, Balaguer JM, et al. Routine intraoperative completion angiography after coronary artery bypass grafting and 1-stop hybrid revascularization: results from a fully integrated hybrid catheterization laboratory/operating room. J Am Coll Cardiol. 2009;53:232-41.

7. Sianos G, Morel MA, Kappetein AP, et al. The SYNTAX score: an angiographic tool grading complexity of coronary artery disease. EuroIntervention. 2005;1: 219-27.

8. Roques F, Nashef SA, Michel P, et al. Risk factors and outcome in European cardiac surgery: analysis of the euroSCORE multinational database of 19,030 patients. Eur J Cardiothorac Surg. 1999;15:816-22.

9. Sarno G, Garg S, Onuma Y, et al. Impact of completeness of revascularization on the five-year outcome in percutaneous coronary intervention and coronary artery bypass graft patients (from the ARTS-II study). Am J Cardiol. 2010;106: 1369-75.

10. Hu S, Li Q, Gao P, et al. Simultaneous hybrid revascularization versus off-pump coronary artery bypass for multivessel coronary artery disease. Ann Thorac Surg. 2011;91:432-9.
11. Nashef SA, Roques F, Hammill BG, et al. Validation of European System for Cardiac Operative Risk Evaluation (euroSCORE) in North American cardiac surgery. Eur J Cardiothorac Surg. 2002;22:101-5.

12. Nilsson J, Algotsson L, Höglund P, et al. Early mortality in coronary bypass surgery: the euroSCORE versus the Society of Thoracic Surgeons risk algorithm. Ann Thorac Surg. 2004;77:1235-9.

13. Wykrzykowska JJ, Garg S, Girasis C, et al. Value of the SYNTAX score for risk assessment in the all-comers population of the randomized multicenter LEADERS (Limus Eluted from A Durable versus ERodable Stent coating) trial. J Am Coll Cardiol. 2010;56:272-7.

\section{APPENDIX 1 \\ Definitions}

Operative mortality: in-hospital death or death for any reason occurring within or after 30 days postoperatively.

Hospital length of stay: hospital length of stay from the date of surgery to the date of discharge.

Hypertension: if there was a documented history of hypertension treated by antihypertensive medication before surgery.

Myocardial infarction (MI): acute if present 7 days or less from the last documented MI or evolving, if, at surgery, Q waves or ST changes were present, along with a creatine kinase-MB greater than $5 \%$ of the total creatine kinase.

Urgent surgery: procedure required during the same hospitalization to minimize the risk of additional clinical deterioration.

Emergent surgery: if ischemic dysfunction (ongoing ischemia despite maximal medical treatment or intra-aortic balloon pump, acute/evolving MI, pulmonary edema requiring intubation), or shock.

Low cardiac output syndrome: a cardiac index of 2.0 $\mathrm{L} / \mathrm{min} / \mathrm{m}^{2}$ or less, requiring triple inotropic support to maintain a systolic pressure greater than $90 \mathrm{~mm} \mathrm{Hg}$ for at least 30 minutes and/or placement of an intra-aortic balloon pump and/or ventricular assist device.

Perioperative MI: appearance of new $\mathrm{Q}$ waves and/or a creatine kinase-MB fraction of $100 \mathrm{IU} / \mathrm{L}$ or greater.

Bleeding: necessity for reexploration of the thorax for suspected bleeding during the postoperative period.

Stroke: evidence in the postoperative period of a new central neurologic deficit persisting for longer than 72 hours; if the neurologic deficit resolved within 72 hours, it was considered a transient ischemic attack.

Acute renal failure: an increase in creatinine to twice the preoperative value. 
APPENDIX TABLE 1. Preoperative, intraoperative, and postoperative data for euroSCORE $<$ /SYNTAX $<32(\mathbf{n}=\mathbf{1 8 7})$

\begin{tabular}{|c|c|c|c|}
\hline Variable & $\begin{array}{c}\text { CABG } \\
(145)\end{array}$ & $\begin{array}{c}\text { HCR } \\
(n=42)\end{array}$ & $\begin{array}{c}P \\
\text { value }\end{array}$ \\
\hline \multicolumn{4}{|l|}{ Preoperative data } \\
\hline Age (y) & $59(32-80)$ & $57.5(39-75)$ & .350 \\
\hline Men & $115(79)$ & $36(86)$ & .505 \\
\hline Diabetes & $52(36)$ & $19(45)$ & .284 \\
\hline Hypertension & $111(77)$ & $37(88)$ & .132 \\
\hline Dyslipidemia & $113(78)$ & $33(79)$ & 1.000 \\
\hline Cardiogenic shock & $1(1)$ & $1(2)$ & .400 \\
\hline CHF & $10(7)$ & $2(5)$ & 1.000 \\
\hline COPD & $24(17)$ & $7(17)$ & 1.000 \\
\hline History of stroke & $8(6)$ & $0(0)$ & .202 \\
\hline PVD & $14(10)$ & $7(17)$ & .264 \\
\hline Carotid artery stenosis & $9(6)$ & $4(10)$ & .493 \\
\hline Inotropic support & $2(1)$ & $1(2)$ & .536 \\
\hline Preoperative IABP & $2(1)$ & $1(2)$ & .536 \\
\hline Valve disease & $13(9)$ & $2(5)$ & .527 \\
\hline Previous cardiac surgery & $0(0)$ & $0(0)$ & \\
\hline Acute MI & $15(10)$ & $4(10)$ & 1.000 \\
\hline UA & $76(53)$ & $19(45)$ & .483 \\
\hline 2-Vessel disease & $40(28)$ & $6(14)$ & .103 \\
\hline$\geq 3$-Vessel disease & $95(66)$ & $35(83)$ & .035 \\
\hline Left main disease & $35(24)$ & $7(17)$ & .402 \\
\hline Proximal LAD & $54(37)$ & $14(33)$ & .718 \\
\hline LVEF & $55(25-70)$ & $55(30-70)$ & .914 \\
\hline Emergent/urgent status & $84(58)$ & $22(52)$ & .597 \\
\hline NYHA class & $2(1-4)$ & $1(1-3)$ & .471 \\
\hline Baseline creatinine $\geq 1.5 \mathrm{mg} / \mathrm{dL}$ & $6(4)$ & $3(7)$ & .423 \\
\hline SYNTAX & $21.5(7-32)$ & $21(12-32)$ & .612 \\
\hline euroSCORE & $3(0-5)$ & $2.5(0-5)$ & .662 \\
\hline \multicolumn{4}{|l|}{ Intraoperative data } \\
\hline Planned HCR & & $32 / 42(76)$ & \\
\hline Off pump & $22(15)$ & $7(17)$ & .811 \\
\hline Grafts (n) & $2(1-5)$ & $2(1-4)$ & .001 \\
\hline OR time (min) & $371(138-664)$ & $403(230-744)$ & .004 \\
\hline CPB time (min) & $90(28-178)$ & $76(33-140)$ & .001 \\
\hline Aortic crossclamp time (min) & $64(20-147)$ & $51(18-111)$ & .001 \\
\hline \multicolumn{4}{|l|}{ Perioperative outcomes } \\
\hline Operative mortality & $1(1)$ & $1(2)$ & .400 \\
\hline Length of stay (d) & $5(3-28)$ & $5(3-97)$ & .993 \\
\hline \multicolumn{4}{|l|}{ Postoperative complications } \\
\hline PCVA & $0(0)$ & $0(0)$ & \\
\hline ARF/RFHD & $4(3)$ & $1(2)$ & 1.000 \\
\hline Bleeding/PRBC $\geq 3 \mathrm{U}$ & $17(12)$ & $8(19)$ & .301 \\
\hline Reoperation for bleeding & $4(3)$ & $3(7)$ & .198 \\
\hline Tracheostomy & $1(1)$ & $1(2)$ & .400 \\
\hline New atrial fibrillation & $25(17)$ & $4(10)$ & .332 \\
\hline PLCOS & $5(3)$ & $0(0)$ & .589 \\
\hline Composite outcome* & $6(4)$ & $2(5)$ & 1.000 \\
\hline
\end{tabular}

Data are presented as the median (range) or number (percentage). euroSCORE, European System for Cardiac Operative Risk Evaluation; SYNTAX, Synergy Between Percutaneous Coronary Intervention With Taxus and Cardiac Surgery; $C A B G$, coronary artery bypass grafting; $H C R$, hybrid coronary revascularization; $C H F$, congestive heart failure; $C O P D$, chronic obstructive pulmonary disease; $P V D$, peripheral vascular disease; $I A B P$, intra-aortic balloon pump; $M I$, myocardial infarction; $U A$, unstable angina; $L A D$, left anterior descending (artery); $L V E F$, left ventricular ejection fraction; NYHA, New York Heart Association (functional classification); $H C R$, hybrid coronary revascularization; $O R$, operating room; $C P B$, cardiopulmonary bypass; $P C V A$, postoperative cerebrovascular accident; $A R F / R F H D$, acute renal failure/renal failure requiring hemodialysis; $P R B C$, packed red blood cells; $P L C O S$, postoperative low cardiac output syndrome. ${ }^{*}$ Composite cardiac and cerebrovascular outcome: operative mortality, MI, PCVA, PLCOS.
APPENDIX TABLE 2. Preoperative, intraoperative, and postoperative data for euroSCORE $>$ 5/SYNTAX $<32(n=106)$

\begin{tabular}{|c|c|c|c|}
\hline Variable & $\begin{array}{c}\text { CABG } \\
(\mathbf{n}=\mathbf{8 1})\end{array}$ & $\begin{array}{c}\text { HCR } \\
(n=25)\end{array}$ & $\begin{array}{c}P \\
\text { value }\end{array}$ \\
\hline \multicolumn{4}{|l|}{ Preoperative data } \\
\hline Age (y) & $72(46-89)$ & $72(45-85)$ & 941 \\
\hline Men & $54(67)$ & $17(68)$ & 1.000 \\
\hline Diabetes & $34(42)$ & $9(36)$ & .648 \\
\hline Hypertension & $75(93)$ & $22(88)$ & .437 \\
\hline Dyslipidemia & $57(70)$ & $16(64)$ & .623 \\
\hline Cardiogenic shock & $2(2)$ & $0(0)$ & 1.000 \\
\hline CHF & $15(19)$ & $3(12)$ & .554 \\
\hline COPD & $24(30)$ & $10(40)$ & .464 \\
\hline History of stroke & $10(12)$ & $3(12)$ & 1.000 \\
\hline PVD & $24(30)$ & $8(32)$ & .808 \\
\hline Carotid artery stenosis & $25(31)$ & $7(28)$ & 1.000 \\
\hline Inotropic support & $1(1)$ & $0(0)$ & 1.000 \\
\hline Preoperative IABP & $6(7)$ & $1(4)$ & 1.000 \\
\hline Valve disease & $21(26)$ & $5(20)$ & .607 \\
\hline Previous cardiac surgery & $0(0)$ & $1(4)$ & .236 \\
\hline Acute MI & $19(23)$ & $7(28)$ & .791 \\
\hline UA & $50(62)$ & $16(64)$ & 1.000 \\
\hline 2-Vessel disease & $27(33)$ & $4(16)$ & .132 \\
\hline$\geq 3$-Vessel disease & $54(67)$ & $20(80)$ & .319 \\
\hline Left main disease & $25(31)$ & $4(16)$ & 201 \\
\hline Proximal LAD & $33(41)$ & $9(36)$ & .816 \\
\hline LVEF & $55(10-65)$ & $50(20-60)$ & .375 \\
\hline Emergent/urgent status & $56(69)$ & $19(76)$ & 619 \\
\hline NYHA class & $2(1-4)$ & $1(1-4)$ & .168 \\
\hline Baseline creatinine $\geq 1.5 \mathrm{mg} / \mathrm{dL}$ & $8(10)$ & $4(16)$ & 471 \\
\hline SYNTAX & $23(11-32)$ & $22(13-31)$ & .797 \\
\hline euroSCORE & $7(6-14)$ & $8(6-12)$ & .641 \\
\hline \multicolumn{4}{|l|}{ Intraoperative data } \\
\hline Planned HCR & & $17 / 25(68)$ & \\
\hline Off pump & $13(16)$ & $8(32)$ & .092 \\
\hline Grafts (n) & $2(1-4)$ & $2(1-5)$ & .001 \\
\hline OR time (min) & $385(234-558)$ & $413(264-593)$ & .038 \\
\hline CPB time (min) & $94(38-284)$ & $76(36-175)$ & .109 \\
\hline Aortic crossclamp time (min) & $62(12-152)$ & $58(21-96)$ & .154 \\
\hline \multicolumn{4}{|l|}{ Perioperative outcomes } \\
\hline Operative mortality & $4(5)$ & $0(0)$ & .571 \\
\hline Length of stay (d) & $6(1-32)$ & $6(3-19)$ & 603 \\
\hline \multicolumn{4}{|l|}{ Postoperative complications } \\
\hline PCVA & $3(4)$ & $1(4)$ & 1.000 \\
\hline $\mathrm{ARF} / \mathrm{RFHD}$ & $4(5)$ & $1(4)$ & 1.000 \\
\hline Bleeding/PRBC $\geq 3 \mathrm{U}$ & $21(26)$ & $4(16)$ & .422 \\
\hline Reoperation for bleeding & $3(4)$ & $0(0)$ & 1.000 \\
\hline Tracheostomy & $1(1)$ & $1(4)$ & .418 \\
\hline New atrial fibrillation & $24(30)$ & $7(28)$ & 1.000 \\
\hline PLCOS & $5(6)$ & $0(0)$ & .590 \\
\hline Composite outcome* & $10(12)$ & $1(4)$ & .452 \\
\hline
\end{tabular}

Data are presented as the median (range) or number (percentage). euroSCORE, European System for Cardiac Operative Risk Evaluation; SYNTAX, Synergy Between Percutaneous Coronary Intervention With Taxus and Cardiac Surgery; $C A B G$, coronary artery bypass grafting; $H C R$, hybrid coronary revascularization; $C H F$, congestive heart failure; $C O P D$, chronic obstructive pulmonary disease; $P V D$, peripheral vascular disease; $I A B P$, intra-aortic balloon pump; $M I$, myocardial infarction; $U A$ unstable angina; $L A D$, left anterior descending (artery); $L V E F$, left ventricular ejection fraction; NYHA, New York Heart Association (functional classification); $H C R$, hybrid coronary revascularization; $O R$, operating room; $C P B$, cardiopulmonary bypass; $P C V A$, postoperative cerebrovascular accident; $A R F / R F H D$, acute renal failure/renal failure requiring hemodialysis; PRBC, packed red blood cells; PLCOS, postoperative low cardiac output syndrome. ${ }^{*}$ Composite cardiac and cerebrovascular outcome: operative mortality, MI, PCVA, PLCOS. 
APPENDIX TABLE 3. Preoperative, intraoperative, and postoperative data for euroSCORE $<5 /$ SYNTAX $>33(n=52)$

\begin{tabular}{|c|c|c|c|}
\hline Variable & $\begin{array}{c}\text { CABG } \\
(n=48)\end{array}$ & $\begin{array}{c}\text { HCR } \\
(n=4)\end{array}$ & $\begin{array}{c}P \\
\text { value }\end{array}$ \\
\hline \multicolumn{4}{|l|}{ Preoperative data } \\
\hline Age (y) & $60(36-80)$ & $59.5(53-64)$ & .877 \\
\hline Men & $42(88)$ & $2(50)$ & .107 \\
\hline Diabetes & $13(27)$ & $2(50)$ & .569 \\
\hline Hypertension & $41(85)$ & $2(50)$ & .134 \\
\hline Dyslipidemia & $42(88)$ & $4(100)$ & 1.000 \\
\hline Cardiogenic shock & $0(0)$ & $0(0)$ & \\
\hline CHF & $3(6)$ & $0(0)$ & 1.000 \\
\hline COPD & $12(25)$ & $0(0)$ & .562 \\
\hline History of stroke & $3(6)$ & $0(0)$ & 1.000 \\
\hline PVD & $3(6)$ & $1(25)$ & .281 \\
\hline Carotid artery stenosis & $4(8)$ & $1(25)$ & 341 \\
\hline Inotropic support & $0(0)$ & $0(0)$ & \\
\hline Preoperative IABP & $0(0)$ & $0(0)$ & \\
\hline Valve disease & $1(2)$ & $0(0)$ & 1.000 \\
\hline Previous cardiac surgery & $1(2)$ & $0(0)$ & 1.000 \\
\hline MI & $2(4)$ & $0(0)$ & 1.000 \\
\hline UA & $21(44)$ & $2(50)$ & 1.000 \\
\hline 2-Vessel disease & $12(25)$ & $1(25)$ & 1.000 \\
\hline$\geq 3$-Vessel disease & $31(65)$ & $3(75)$ & 1.000 \\
\hline Left main disease & $20(42)$ & $1(25)$ & .639 \\
\hline Proximal LAD & $13(27)$ & $1(25)$ & 1.000 \\
\hline LVEF & $53(15-70)$ & $47.5(45-55)$ & .507 \\
\hline Emergent/urgent status & $28(58)$ & $2(50)$ & 1.000 \\
\hline NYHA class & $2(1-3)$ & $1.5(1-3)$ & .755 \\
\hline Baseline creatinine $\geq 1.5 \mathrm{mg} / \mathrm{dL}$ & $5(10)$ & $0(0)$ & 1.000 \\
\hline SYNTAX & $36(33-46.5)$ & $36.8(34-41)$ & .809 \\
\hline euroSCORE & $3(0-5)$ & $2.5(1-4)$ & .780 \\
\hline \multicolumn{4}{|l|}{ Intraoperative data } \\
\hline Planned HCR & & $2 / 4(50)$ & \\
\hline Off pump & $5(10)$ & $0(0)$ & 1.000 \\
\hline Grafts (n) & $2(1-4)$ & $1(1-2)$ & .005 \\
\hline OR time (min) & $379(250-667)$ & $394(370-437)$ & .607 \\
\hline CPB time (min) & $91(49-153)$ & $67(50-93)$ & .079 \\
\hline Aortic crossclamp time (min) & $65(31-108)$ & $40(32-75)$ & .090 \\
\hline \multicolumn{4}{|l|}{ Perioperative outcomes } \\
\hline Operative mortality & $0(0)$ & $1(25)^{*}$ & .077 \\
\hline Length of stay (d) & $5(3-33)$ & $6.5(5-32)$ & .132 \\
\hline \multicolumn{4}{|l|}{ Postoperative complications } \\
\hline PCVA & $1(2)$ & $0(0)$ & 1.000 \\
\hline ARF/RFHD & $2(4)$ & $0(0)$ & 1.000 \\
\hline Bleeding/PRBC $\geq 3 \mathrm{U}$ & $7(15)$ & $0(0)$ & 1.000 \\
\hline Reoperation for bleeding & $0(0)$ & $0(0)$ & \\
\hline Tracheostomy & $1(2)$ & $1(25)$ & .149 \\
\hline New atrial fibrillation & $12(25)$ & $1(25)$ & 1.000 \\
\hline PLCOS & $3(6)$ & $0(0)$ & 1.000 \\
\hline Composite outcome $\dagger$ & $4(8)$ & $1(25)$ & .341 \\
\hline
\end{tabular}

Data are presented as the median (range) or number (percentage). euroSCORE, European System for Cardiac Operative Risk Evaluation; SYNTAX, Synergy Between Percutaneous Coronary Intervention With Taxus and Cardiac Surgery; $C A B G$, coronary artery bypass grafting; $H C R$, hybrid coronary revascularization; $C H F$, congestive heart failure; $C O P D$, chronic obstructive pulmonary disease; $P V D$, peripheral vascular disease; $I A B P$, intra-aortic balloon pump; $M I$, myocardial infarction; $U A$, unstable angina; $L A D$, left anterior descending (artery); $L V E F$, left ventricular ejection fraction; $N Y H A$, New York Heart Association (functional classification); $H C R$, hybrid coronary revascularization; $O R$, operating room; $C P B$, cardiopulmonary bypass; $P C V A$, postoperative cerebrovascular accident; $A R F / R F H D$, acute renal failure/renal failure requiring hemodialysis; PRBC, packed red blood cells; PLCOS, postoperative low cardiac output syndrome. *Respiratory failure. $\dagger$ Composite cardiac and cerebrovascular outcome: operative mortality, MI, PCVA, PLCOS.
APPENDIX TABLE 4. Preoperative, intraoperative, and postoperative data for euroSCORE $>5 /$ SYNTAX $>33(n=36)$

\begin{tabular}{|c|c|c|c|}
\hline Variable & $\begin{array}{c}\text { CABG } \\
(\mathbf{n}=\mathbf{2 7})\end{array}$ & $\begin{array}{c}\text { HCR } \\
(\mathbf{n}=9)\end{array}$ & $\begin{array}{c}P \\
\text { value }\end{array}$ \\
\hline \multicolumn{4}{|l|}{ Preoperative data } \\
\hline Age (y) & $65(45-83)$ & $77(47-84)$ & .001 \\
\hline Men & $20(74)$ & $6(67)$ & .686 \\
\hline Diabetes & $11(41)$ & $2(22)$ & .438 \\
\hline Hypertension & $24(89)$ & $8(89)$ & 1.000 \\
\hline Dyslipidemia & $17(63)$ & $5(56)$ & .712 \\
\hline Cardiogenic shock & $1(4)$ & $0(0)$ & 1.000 \\
\hline CHF & $7(26)$ & $1(11)$ & .648 \\
\hline COPD & $11(41)$ & $2(22)$ & .438 \\
\hline History of stroke & $7(26)$ & $2(22)$ & 1.000 \\
\hline PVD & $8(30)$ & $3(33)$ & 1.000 \\
\hline Carotid artery stenosis & $6(22)$ & $1(11)$ & .652 \\
\hline Inotropic support & $2(7)$ & $0(0)$ & 1.000 \\
\hline Preoperative IABP & $2(7)$ & $0(0)$ & 1.000 \\
\hline Valve disease & $6(22)$ & $2(22)$ & 1.000 \\
\hline Previous cardiac surgery & $2(7)$ & $0(0)$ & 1.000 \\
\hline MI & $7(26)$ & $2(22)$ & 1.000 \\
\hline UA & $13(48)$ & $4(44)$ & 1.000 \\
\hline 2-Vessel disease & $2(7)$ & $2(22)$ & .255 \\
\hline$\geq 3$-Vessel disease & $24(89)$ & $7(78)$ & .581 \\
\hline Left main disease & $10(37)$ & $2(22)$ & .685 \\
\hline Proximal LAD & $13(48)$ & $3(33)$ & .700 \\
\hline LVEF & $43(10-70)$ & $55(20-65)$ & .069 \\
\hline Emergent/urgent status & $10(37)$ & $5(56)$ & .443 \\
\hline NYHA class & $2(1-4)$ & $2(1-3)$ & .120 \\
\hline Baseline creatinine $\geq 1.5 \mathrm{mg} / \mathrm{dL}$ & $7(26)$ & $0(0)$ & .156 \\
\hline SYNTAX & $36.5(33-56)$ & $35.5(33-44.5)$ & .621 \\
\hline euroSCORE & $7(6-15)$ & $9(6-14)$ & .562 \\
\hline \multicolumn{4}{|l|}{ Intraoperative data } \\
\hline Planned HCR & & 9/9 (100) & \\
\hline Off pump & $7(26)$ & $4(44)$ & .409 \\
\hline Grafts (n) & $2(1-5)$ & $1(1-2)$ & .027 \\
\hline OR time (min) & $377(275-519)$ & $423(294-549)$ & .522 \\
\hline CPB time (min) & $91(32-141)$ & $60(58-159)$ & .659 \\
\hline Aortic crossclamp time (min) & $57(21-97)$ & $38(23-74)$ & .377 \\
\hline \multicolumn{4}{|l|}{ Perioperative outcomes } \\
\hline Operative mortality & $0(0)$ & $2(22)$ & .057 \\
\hline Length of stay (d) & $6(4-63)$ & $6(1-25)$ & .630 \\
\hline \multicolumn{4}{|l|}{ Postoperative complications } \\
\hline PCVA & $0(0)$ & $1(11)$ & .250 \\
\hline ARF/RFHD & $2(7)$ & $0(0)$ & 1.000 \\
\hline Bleeding/PRBC $\geq 3 \mathrm{U}$ & $3(11)$ & $4(44)$ & .050 \\
\hline Reoperation for bleeding & $0(0)$ & $0(0)$ & \\
\hline Tracheostomy & $0(0)$ & $1(11)$ & .250 \\
\hline New atrial fibrillation & $5(19)$ & $3(33)$ & .384 \\
\hline PLCOS & $0(0)$ & $2(22)$ & .057 \\
\hline Composite outcome* & $0(0)$ & $3(33)$ & .012 \\
\hline
\end{tabular}

Data are presented as the median (range) or number (percentage). euroSCORE, European System for Cardiac Operative Risk Evaluation; SYNTAX, Synergy Between Percutaneous Coronary Intervention With Taxus and Cardiac Surgery; $C A B G$, coronary artery bypass grafting; $H C R$, hybrid coronary revascularization; $C H F$, congestive heart failure; $C O P D$, chronic obstructive pulmonary disease; $P V D$, peripheral vascular disease; $I A B P$, intra-aortic balloon pump; $M I$, myocardial infarction; $U A$, unstable angina; $L A D$, left anterior descending (artery); $L V E F$, left ventricular ejection fraction; NYHA, New York Heart Association (functional classification); $H C R$, hybrid coronary revascularization; $O R$, operating room; $C P B$, cardiopulmonary bypass; $P C V A$, postoperative cerebrovascular accident; $A R F / R F H D$, acute renal failure/renal failure requiring hemodialysis; PRBC, packed red blood cells; PLCOS, postoperative low cardiac output syndrome. ${ }^{*}$ Composite cardiac and cerebrovascular outcome: operative mortality, MI, PCVA, PLCOS. 